\title{
POR UM NOVO CONCEITO DE SERVIDOR PÚBLICO
}

\author{
ALBERTO NOGUEIRA JÚNIOR \\ I - Introdução. II - Quem é servidor público? - Notas de referência
}

\section{I- Introdução}

O que se deve entender por servidor público?

A pergunta é simples, mas a resposta, como se verá, está longe de sê-la. Na realidade, o termo - servidor público - não possui significado unívoco - e isto sob qualquer enfoque que se queira dar, doutrinário, histórico - legal ou jurisprudencial.

Mas não só o termo servidor público é polissêmico - seus vários significados, por vezes contraditórios entre si, comportam aplicação a um mesmo tempo, e não tão ocasionalmente como se poderia esperar, para uma mesma situação fático jurídica.

Disto resulta favorecimento à insegurança jurídica; tratamento e sancionamento diversos para situações objetivamente idênticas e bens jurídicos lesados idem; e maior incompreensão sobre o servidor público já no seu início, ou seja, sobre quem deverá ser como tal considerado.

Não é só.

A polissemia conceitual, não raro contraditória, existente dentro da órbita da estrutura administrativa do Estado, pode contaminar as relações privadas que já começam a formar-se fora daquela estrutura, com o incentivo estatal, de acordo com políticas de descentralização administrativa que já estão a se desenvolver.

Esta a preocupação que motivou a realização deste trabalho.

Dados os limites desta exposição, serão feitas "pequenas incursões" nos âmbitos doutrinario, normativo e jurisprudencial, comparativamente e a título ilustrativo. 
Busca-se. como conclusão, provocar uma redefinição do conceito de servidor público, acentuando-se o enfoque já não tanto no aspecto de exercente de autoridade pública para o atingimento de fins também públicos. mas sim nos de função dever. a impor, inclusive a particulares, obrigações. ônus. deveres, restrições e sançōes, como se integrantes dos quadros da Administração Pública fossem. (1)

\section{II - Quem é servidor público?}

Nossa sintética exposição começa por uma pequena incursão na doutrina, onde, como dito por Odete Medauar (2). "reina confusão" sobre se o pessoal da Administração Pública Indireta pode ser considerado "servidor público" em sentido amplo.

Assim diz a autora:

"Na linguagem técnico-juridica reina confusão, parecendo difícil fixar com nitidez o sentido da diversas expressões existentes. A CF dá preferência à expressão "servidores públicos", com a qual intitula uma seção; usa também o termo "servidor" em quase todos os dispositivos da matéria. Assim, a CF atribui a essa locução o sentido amplo, que tradicionalmente se conferia à expressão "agentes públicos", para abranger todos aqueles que mantêm vinculo de trabalho com o poder público. Em textos legais menos recentes, é dado sentido amplo à expressão "funcionário público", pois era a de uso mais frequiente antes da CF de 1988; p. ex., o art. 327 do Código Penal." (op. cit., p. 295/296)

Acabando por concluir no sentido de que a locução "servidores públicos":

“... $\mathrm{Na} \mathrm{CF}$ de 1988 designa todas as pessoas físicas que trabalham nos entes estais, de qualquer poder, inclusive os detentores de cargos: e o mesmo sentido de locução "agentes públicos". Antes da CF de 1988, a doutrina atribuía tal nome àqueles que trabalhavam nos entes estatais, sem ocuparem cargos, p. ex., os contratados." (3)

Há quem, como Pedro Nunes (4), apresente ambos os termos como de idêntico significado:

"SERVIDOR PÚBLICO - É todo aquele que, investido de qualquer cargo, ofício ou função pública em caráter efetivo ou temporário. integrado ou não no quadro dos funcionários públicos, é remunerado ou não pelos cofres públicos. O mesmo que funcionário público."

Recusando esta identificação entre o pessoal da Administração Direta e da Administração Indireta, José dos Santos Carvalho Filho (5):

"Sem embargo de respeitáveis opiniōes em contrário (Celso Antônio Bandeira de Mello, op. cit., p. 124, e Maria Sylvia Zanella di Pietro, ob. cit., pág. 306), não consideramos servidores públicos os empregados das emi- 
dades privadas da Administração Indireta, caso das empresas públicas. sociedades de economia mista e fundações públicas de direito privado. Todos são sempre regidos pelo regime trabalhista, integrando a categoria profissional a que estiver vinculada a entidade, como a de bancários, economiários, securitários, etc. Além do mais, o art. 173, § $I^{\circ}$ da CF estabelece que empresas públicas e sociedades de economia mista devem sujeitar-se às regras de direito privado quanto às obrigaçōes trabalhistas. São, portanto, empregados normais. Por fim, a própria tradição do direito brasileiro nunca enquadron tais empregados como servidores públicos, nem em sentido lato. Com o mesmo entendimento, Hely Lopes Meirelles (op. cit., p. 359)"

Hely Lopes Meirelles. citado por José dos Santos Carvalho Filho, define serem "Servidores públicos" os "agentes públicos administrativos" (6), categoria esta que se constitui na "imensa massa dos prestadores de serviços à Administração direta $e$ indireta do Estado nas seguintes modalidades admitidas pela Constituição da República de 1988: a) servidores públicos concursados (art. 37, II); b) servidores públicos exercentes de cargo em comissão ou função de confiança. sem concurso, escolhidos, preferencialmente, entre "senidores ocupantes de cargo de carreira técnica ou profissional" (art. 37, V); c) servidores temporários, contratados "por tempo determinado para atender a necessidade temporária de excepcional interesse píblico" (art. 37, IX)".

Parece, entretanto. ter sido equivocada a referência feita por JOsé dos Santos Carvalho Filho a Celso Antônio Bandeira de Mello, já que este afirma serem "servidores públicos civis" "os senidores da administração direta, das autarquias e das fundações públicas" (8), excluindo do conceito, portanto, o pessoal de qualquer ente de direito privado.

Por outro lado, a "confusão" apontada por Odete Medauar no âmbito doutrinário não vem de hoje.

Assim. por exemplo, Augusto Olympio Viveiros de Castro (9) adverte:

"Cumpre, porém. atender-se que a fraseologia da nossa legislação administrativa não está inteiramente assentada sobre esta matéria.

"Geralmente as palavras - empregados públicos - designam não só esta classe especial de agentes da administração, como também todos os seus funcionários, diretos ou indiretos.

"Assim também a palavra- funcionários - é empregada algumas vezes para designar não só os que assim tecnicamente se denominam, como quaisquer empregados públicos; e a expressão - funções públicas - para indicar as atribuições e actos dos cargos públicos de qualquer categoria. (...)".

Admitindo serem "servidores" também o pessoal autárquico, Caio Tácito (10): 
“2 - É oportuno salientar, desde logo, que a condição de servidor autárquico indicada na consulta não altera os termos do problema. O regime jurídico da função pública exercida nos órgãos de administração descentalizada se assemelha aos dos servidores da Administração direta do Estado. Tanto para efeitos penais (art. 327 do Código Penal), como administrativos, unificou-se o tratamento jurídico das duas categorias de servidores públicos em sentido lato. A legislação peculiar à função pública direta constitui normas supletiva aplicável, por exensão, aos servidores autárquicos."

Maria Sylvia Zanella di Pietro firma que "são servidores públicos, em sentido amplo, as pessoas físicas que prestam serviços ao Estado e às entidades da Administração indireta, com vínculo empregatício e mediante remuneração paga pelos cofres públicos". (11)

Esclarecendo que, "na vigência da Constituição anterior, dizia-se que funcionário público só existia na Administração direta (incluindo Executivo, Judiciário e Legislativo), pois apenas ele ocupava cargo público crido por lei e se submetia ao Estatuto dos Funcionários públicos; os servidores autárquicos ou tinham regime estatutário próprio ou se submetiam à CLT, sendo seus cargos criados pelo Poder Público". (12)

Idêntica confusão conceitual é observada no âmbito da legislação.

Sempre restringindo a aplicação do método comparativo a "pequenas incursões", iniciamos estas com o exame do art. 327 do CP.

Para fins penais, o referido artigo estabece equiparação dos "servidores" aos "funcionários", que são os servidores regidos por estatuto legal próprio, enquanto que, de regra, os "senvidores" têm suas relações jurídicas para com a Administração Pública regidas pela CLT - digo "de regra" porque, com o advento da Emenda Constitucional $n^{\circ} 19 / 98$, tornou-se possível aos entes políticos criarem outras espécies de regimes jurídicos, como o "terceiro regime jurídico" preconizado por Carlos Motta/jorge Jacoby/Jair Santana/Léo Alves, (13) — mas a equiparação só atingiria o pessoal autárquico, "não se aplicando às sociedades de economia mista ou àquelas em que o poder público figura como acionista majoritário", uma vez que trata de "extensão, conceituando a elementar funcionário público contida em várias incriminações", daí porque, constituindo-se em "norma penal incriminadora", "sua interpretação deve ser restritiva, não podendo ser alargada". (14)

Em sentido contrário, Julio Fabbrini Mirabete (15), que diz:

“(...) Embora a interpretação literal do $\S 1^{\circ}$ do artigo 327 não deixe dúvidas quanto à inclusão no conceito de funcionário público, para os efeitos penais, das pessoas que exercem cargo, emprego ou função pública nessas entidades paraestatais, há na doutrina séria resistência em abrangê-las na definição. Fragoso afirma que, realizando essas entidades serviços industriais ou comerciais que não constituem fins próprios do Estado e que não configuram função pública para os efeitos da lei a ampliação é inadmissível. Ana Maria Mabette Fernandes, afirmando que na elaboração do Código Penal não se previa o desenvolvimento "desenfreado" da estrutura burocrática do Estado, 
repele a solução normal da interpretação progressista, recomendando que se restrinja o conceito. (...)".

Com o que a imprecisão resultante da multiplicidade de significados acima ilustrada permitiria a não - responsabilização penal de alguém que tivesse lesado bens de entidades de direito publico, ou cuja proteção e preservação fosse de interesse social - ao menos, não da mesma forma como se poderia resonsabilizar alguém que fosse considerado servidor público - e isto em que pese a identidade do fato criminoso.

Os reflexos da discrepância conceitual existente em todos os níveis espraiam-se, como não podia deixar de ser, na jurisprudência, ora perfilhando-se num sentido, ora noutro, e com isto, penso, enfraquecendo-se o princípio da segurança jurídica, bem como a efetiva proteção aos bens jurídicos tutelados.

Assim, e.g., a $1^{\text {a }}$ Turma do Eg. STF, quando do julgamento do RE no. 96803-PE, Rel. Min. Soares Muñoz, dec. un. pub. DJU de 18.06.1982, Seção 1, p. 5.989 e in RTJ 103-02, p. 864, decidiu que a "apropriação de dinheiro pertencente à Empresa Brasileira de Correios e Telégrafos, pratica por empregado da mencionada entidade no exercício de suas funções", caracateriza "crime de peculato e não de apropriação indébita", aplicando-se, pois, os arts. 312 e 327 do CP.

Mas a $1^{\text {a }}$ Turma do Eg. TFR, quando do julgamento da Apelação Criminal no. 4167-RJ, dec. un. pub. DJU de 26.03.1981, decidiu que "inexiste peculato, mas apropriação indébita de valores da ECT, se o delito não é praticado em detrimento dos serviços postais e de telecomunicações, que ela executa por delegação da União".

E em que pese a amplitude literal dada pelo art. 327 do CPC, considerando ser "funcionário público" "quem, embora transitoriamente ou sem remuneração, exerce cargo, emprego ou função pública", não há que se olvidar de outra dificuldade, esta consistente na própria determinação sobre se a entidade que sofreu o fato ilícito pertence, ou não, ã Administração Pública, o que nem sempre é de fácil constatação a priori, demandando às vezes considerável esforço hermenêutico do intérprete, $\mathrm{e}$ com isto novamente enfraquecendo-se o princípio da segurança jurídica e a efetiva tutela daqueles bens jurídicos.

É esta a situação das denominadas "empresas sob controle", que podem ser exemplificadas com a VASP, antes de sua privatização, ocorrida em setembro de 1990, como defendido pelo Exmo. Sr. Procurador Geral da Fazenda Nacional no item 136 de seu Parecer, em Ação Civil Pública proposta pelo Ministério Público Federal visando a anulação de contrato de refinanciamento da dívida daquela empresa com o Tesouro Nacional, por intrmédio do Banco do Brasil S/A e tendo como fiador o Estado de São Paulo. (16)

Transcrevo o item do mencionado Parecer:

“136. Patente, pois, no caso da VASP que, inobstante não haja sido criada por lei, desde a edição da lei estadual autorizativa da assunção de seu controle acionário pelo Estado de São Paulo (Lei no. 2.561, de 10.01.36, já citada), sempre integrou a Administração Indireta daquele Estado, já que não só deteve ele o poder de comando sobre suas operações e sua adminis- 
tração como ainda se dedicou a empresa à finalidade exclusiva da prestação de um serviço público à aviação aérca, mediante concessão das autoridade federais".

Já no caso da COBAL - Companhia Brasileira de Alimentos. a conclusão judicial foi algo diversa.

Assim foi a decisão proferida pela $1^{a}$ Turma do Eg. TFR, quando do julgamento da ACR n 3839-RJ. dec. pub. DJU de 19.03.1981:

"PENAL. COMPANHIA BRASILEIRA DE ALIMENTOS (COBAL). PECULATO. FUNCIONÁRIO PÚBLICO EQLIPARADO. DESCLASSIFICAÇÃO PARA APROPRIAÇÃO INDÉBITA. SUSPENSÃO CONDICIONAL DA PENA. 1) Desclassifica-se a imputação de peculato para apropriação indébita, porquanto o réu não é empregado de entidade paraestatal, isto é, autarquia, não sendo funcionário público sequer por equiparação $(C P$. art. 327. parágrafo único), pois a Companhia Brasileira de Alimentos - COBAL - não exerce qualquer função delegada do Estado. Sua finalidade é agir como elemento regulador do mercado. mediante a utilização da lei da oferta e da procura. na comercialização de gêneros alimentícios. bem assim suprir áreas não suficientemente atendidas por empresas comerciais privadas. mas sempre "em regime competitivo" (Lei Delegada $1^{\circ}$ 06/82. art. $2^{\circ}$ ). Assim. por mais relevantes que sejam as atribuiçoes da Companhia, não se pode entender que exerça função pública delegada qualquer empregado seu, pois o Estado não é comerciante. tem outras finalidades. 2) Suspensão condicional da pena (CP. art. 57 e CPP. art. 696 e segs.)".

Continuando com nossa pequena "incursão".

A Lei ${ }^{\circ} 3.502$. de 22.12.1958, republicada no Diário Oficial de 20.05.1959 e de 09.07.1959. em seu art. $1^{\circ}$, "caput". identificou como sujeito ativo das condutas ali sancionadas o "servidor público", o "dirigente" e o "empregado de autarquia": no $\$ 1^{\circ}$ deste mesmo artigo, definiu o "servidor público" como "todas as pessoas que exercem na União, nes Estados. nos Territórios, no Distrito Federal e nos municipios quaisquer cargos, funçöes ou empregos, ciris ou militares, quer sejam eletivos, quer de nomeaçäo ou contrato. nos órgäos dos Poderes Executivo. Legislativo ou Judiciário"; e equiparou, no $\$ 2^{\circ}$ deste artigo. " ao dirigente ou empregado de autarquia". para os fins da lei. "o dirigente out empregado de sociedade de economia mista, de fundaçäo instirurda pelo Poder Público, de empresa incorporada ao partimônio publico, ou de éntidade que receba é aplique contribuiçöes parafiscais".

Poder-se-ia compreender como "servidor público". dada a menção diferenciada feita pelo art. 1'. "caput" desta lei, apenas ofuncionário, regido por estanuro próprio, cistinguindo-se por este elemento dos cimpregados autárquicos.

Mas esta interpretação restritiva é desautorizada pelo $\$ 2^{\circ}$ o qual. por sua vez, fez incluir no conceito de "servidor píblico" todas as espécies de vínculos diretos possiveis com a Administração Pública. 
E a ampliação chegou ao máximo com o $\$ 3^{\circ}$. que equiparou àquele universo o pessoal da Administração Pública Indireta regida pelo direito privado, assim como os particulares em colaboração com o Poder Público, que dele recebam e apliquem contribuições parafiscais.

A Lei de Responsabilidade Fiscal - Lei Complementar $n^{\circ} 101$. de 04.05.2000 - é aplicável, consoante o seu art. $1^{\circ}$. $\$ 3^{\circ}$, letras " $c$ " e " $b$ ", aos Poderes Executivo, Legislativo, "neste abrangidos os Tribunais de Contas" e Judiciário; ao Ministério Público: e "às respectivas administrações diretas, fundos, autarquias, fundações e empresas estatais dependentes".

$\mathrm{O}$ art. $2^{\circ}$. inciso III, define "empresa estatal dependente" a "empresa controlada que receba do ente controlador recursos financeiros para pagamento de despesas com pessoal ou de custeio em geral ou de capital, excluídos. no último caso, aqueles provenientes de aumento de participação acionária".

E estabelece. em seu art. $18, \S 1^{\circ}$, que "os valores dos contratos de terceirização de mão-de-obra a que se referem à substituição de servidores e empregados públicos seräo contabilizados como "Outras Despesas de Pessoal".

Para os fins da Lei de Responsabilidade Fiscal, portanto. também o pessoal de empresa privada prestadora e executora de serviços da Administração Pública Direta e Indireta, de forma terceirizada, será considerado "pessoal" substituto de "servidores e empregados públicos" e, em atenção ao objetivo de controle orçamentário, não haverá distinção entre pessoal vinculado direta ou indiretamente à Administração Pública, e terceiros particulaes em colaboração com a Administração Pública, seja ela direta, seja indireta - repare-se, ainda, que o art. $18, \S 1^{\circ}$, aparentemente diferencia os "empregados públicos" dos "servidores públicos". embora, a partir da reforma introduzida pela Emenda $n^{\circ} 19 / 98$. tenha voltado a ser possivel a contratação de pessoal. pelo regime da CLT ou outro qualquer, inclusive no âmbito da Administração Pública Direta, situação esta que a doutrina entendia inserir-se no conceito de "servidores públicos".

A Lei $n^{\circ} 8.027$, de 12.04.1990, que dispôs sobre "normas de conduta dos servidores públicos civis da União, das autarquias e das fundações públicas", em seu art. $1^{\circ}$, definiu "servidor público" como "a pessoa legalmente investida em cargo ou emprego público na Administração Direta, nas autarquias ou nas fundaçōes públicas".

Já a Lei no. 8.429, de 02.06.1992. em seu art. $2^{\circ}$, reputou "agente público" "todo aquele que exerce, ainda que transitoriamente ou sem remuneração, por 'seição, nomeação. designação, contratação ou qualque' outra forma de investidura ou vínculo, mandato. cargo, emprego ou função" nas entidades mencionadas no art. $1^{\circ}$, quais sejam: "... a administração direta, indireta ou fundacional de qualquer dos Poderes da União, dos Estados, do Distrito Federal, dos Municipios, de Território, de empresa incorporada ao patrimônio puiblico ou de entidade para cuja criação ou custcio o erário haja concorrido ou concorra com mais de cinqüenta por cento do patrimônio ou da receita anual".

A Lei. portanto, mantendo a atecnicidade verificada já sob a vigência da Lei no. 3.502/58, não só confundiu os "agentes públicos" com os "agentes políticos" (17), adotando aquele termo também para estes. como, ainda, estendeu o significado do conceito de — "agentes públicos" — também para o pessoal de "empresa 
incorporada ao patrimônio público ou de entidade para cuja criação ou custeio o erário haja concorrido ou concorra com mais de cinqüenta por cento do patrimônio ou da receita anual".

$\mathrm{O}$ art. 11, inciso III deste mesmo diploma estabeleceu constituir ato de improbidade administrativa atentatório dos princípios da Administração Pública, o ato de "revelar fato ou circunstância de que tem ciência em razão das atribuições e que deva permanecer em segredo".

Em matéria fiscal, contudo, a Lei Complementar $n^{\circ} 104$, de 10.01.2001, fixou, como sujeitos ativos da infração administrativa de quebra de sigilo, a "Fazenda Pública" ou "seus servidores", consoante a nova redação dada ao art. 198 do CTN.

Houve, creio, redução do rol de sujeitos ativos, em comparação com o disposto nos arts. $1^{\circ}$ e $2^{\circ}$ da Lei no. 8.429/92, não havendo dúvida possível de que a Lei Complementar, no particular, deva prevalecer sobre a lei ordinária, sob todos os prismas que se quiser utilizar para chegar a uma conclusão.

A Lei Complementar é de hierarquia superior à lei ordinária.

Ainda que tal não se desse, seu conteúdo é mais específico do que o que foi tratado na lei ordinária.

E ainda que assim também não se entendesse, é a Lei Complementar $n^{\circ} 104 / 2001$ posterior à Lei no. 8.429/92.

O porquê desta redução é com que não se consegue atinar, a não ser - como tantas vezes dito até aqui - o tratamento desconexo, confuso, por vezes - como neste exemplo - até mesmo contraditório, dado à conceituação do servidor público e à regulamentação legislativa dada a ele.

A Emenda n ${ }^{\circ} 19 / 98$ foi o ápice legislativo e corolário da chamada "Administração Gerencial", cujos contornos foram expostos por Luiz Carlos Bresser Pereira e Peter Spink (org.), "Reforma do Estado e Administração Pública Gerencial", Rio de Janeiro, FGV, 1998.

Examinando a estratégia que esses autores apresentam para se "reformar o aparelho do Estado" -

“(...) Uma estratégia essencial ao se reformar o aparelho do Estado é reforçar o núcleo estratégico e fazer com que seja ocupado por servidores públicos altamente competentes, bem treinados e bem pagos; com servidores que entendam o ethos do serviço público como o dever de servir ao cidadão. Nessa área, a carreira e a estabilidade devem ser asseguradas por lei, embora os termos "carreira" e "estabilidade" devam ser entendidos de modo mais flexivel, se comparados com os seus correspondentes na tradicional administração burocrática. Nas atividades exclusivas, a administração deve ser descentralizada; nos serviços não exclusivos, a administração deve ser mais que descentralizada - deve ser autônoma; a sociedade civil dividirá, com o governo, as tarefas de controle." (op. cit., p. 34).

Francisco Mauro Dias (18) "inobstante a perplexidade", estabelece como premissa para o estudo do tema que esta óptica tornou "agente público por servidores 
civis de cúpula elou servidores civis altamente competentes, com "carreira" $e$ "estabilidade" asseguradas por lei, embora flexibilizadas".

O que torna a ilustrar a "confusão" conceitual, a legitimar a "perplexidade" do ilustre autor, para dizer ao menos, que gira em torno do tema da conceituação do servidor público.

A Lei Complementar $n^{\circ} 104$, de 10.01.2001, alertou a redação dos arts. 198, §§ $1^{\circ}$, incisos I e II, $1^{\circ}$ e $3^{\circ}$, incisos I a III; e do art. 199, parágrafo único, do CTN.

$\mathrm{O}$ art. 198 do CTN, "caput", passou a proibir "a divulgação, por parte da Fazenda Pública ou de seus servidores, de informação obtida em razão de ofício sobre a situação econômica ou financeira do sujeito passivo ou de terceiros e sobre a natureza e o estado de seus negócios ou atividades".

Deixou de haver a referência à proibição desta divulgação " para qualquer fim"; a menção a "qualquer informação"; substituiu-se o termo "funcionários" por "servidores".

As duas primeiras modificações parecem ter apenas melhorado a redação do dispositivo. De fato, se é "vedada a divulgação", não há motivo para entender-se que esta proibição não alcançaria "qualquer fim", salvo exceção expressa de norma legal; da mesma forma, não havendo exceção anteriormente estabelecida no texto do "caput" do referido artigo, inexistiria razão lógica, quanto mais necessidade, de se reiterar que a vedação abrangeria "qualquer informação"; desde que houvesse sido obtida "em razãa do ofício sobre a situação econômica ou financeira do sujeito passivo ou de terceiros e sobre a natureza e o estado de seus negócios ou atividades", toda e qualquer informação estaria abrangida pelo dever de sigilo.

De forma simples, mas como sempre precisa, Aliomar Baleeiro (19) esclarece ser "vedado à pessoa de Direito Público divulgar informação obtida em razão do ofício, o mesmo aplicando-se às autoridades, estas como órgão imediato da pessoa de Direito Público, e aos funcionários, estes como agentes técnicos e jurídicos dela".

Para o que interessa mais diretamente a este trabalho, chamo a atenção para o fato de que a norma referida destina-se apenas aos "servidores da Fazenda" e às "autoridades".

É oportuno lembrar, ainda, que o preceito contido no art. 198 do CTN, com a redação da dada pela LC $n^{\circ} 104 / 2001$, não abrange os particulares que executarem indiretamente serviços para a Fazenda Pública, como empregados de pessoas jurídicas prestadoras de serviços, em regime denominado de "terceirização".

Se a execução do serviço é idêntica, tanto a prestada por "servidores da Fazenda", como por pessoal "terceirizado", penso que também estes últimos deveriam sofrer as mesmas restrições de natureza ética que os primeiros, já que lidam com as mesmas informações e podem, em tese, vir a cometer as mesmas infrações de divulgação indevida daquelas, com idêntica quebra do princípio da confiança do público na Administração Pública.

Não se pode olvidar que o dever de sigilo profissional tem inegável conteúdo ético-normativo. (20)

Como justificar, então, que para fiscais exista tal valoração ético-normativa senão apenas para os servidores da Fazenda Pública, nos termos do "capui" do referido artigo 198, passível de extensão, quando muito, para a autoridade solicitante, 
a que se refere o $\$ 2^{\circ}$ do mesmo artigo, ou para a autoridade administrativa no interesse da Administração Pública e, neste último caso. desde que seja comprorada a instauração regular de processo administrativo, no árgão on na entidade réspectiva, com o objetivo de investigar o sujeito passivo a que se refere a informação. por prática de infração administratika, no dizer o inciso Il daquele mesmo artigo. se o serviço executado, ao fim e ao cabo. é o mesmo?

Insista-se: porque o tratamento ético diferenciado - e verdadeiramente negligenciado no caso de execução de serviços por pessoal " terceirizado" — se os bens jurídicos a serem protegidos são os mesmos: a confiança đo público na Administração Pública, e a proteção ao direito à privacidade dos cidadãos em suas relaçôes com aquela Administração?

Não há qualquer sentido em que. por uma mesma conduta legal e eticamente ilicita. possa eventualmente vir o infrator da ordem jurídica a merecer enquadramento e sanções distintas. mais ou menos graves, apenas por encontrar-se dentro ou fora da estrutura administrativa tradicional.

A esta altura, parece ser intuitivo que, além de significado variável ao longo do tempo e, inclusive, dentro de um ordenamento jurídico vigente em um mesmo tempo, aú tradicional enquadramento do serridor público, seja como funcionário, seja como empregado público, outras situações demandam ser incluidas naquele primeiro termo, especialmente se for considerado que já estamos vivendo uma época de de'olução de funções, ações e poderes a entes sociais. em fenômeno que Diogo de Figueiredo Moreira Neto chama de descentralização social. (21)

E creio ter demonstrado, em que pesem as limitações de espaço aludidas, que o correto entendimento do termo - "scrvidor público" - muito ao invés de constituir-se em preocupação meramente academicista, possui relevância prática c primordial quanto a vários aspectos da atuação da Administração Pública em geral. dentre os quais destacamos os pertinentes à responsabilidade penal, aos controles orçamentários e ao dever funcional de sigilo. atuação está que já está a transbordar os limites da área pública. para imiscuir-se no âmbito privado e com ele confundir-se. aqui e ali, tornando mais do que nunca necessíria a formulação de novo conceito para o servidor público.

\section{Notas de referencia}

(1) A insuficiência do mero aspecto do exercicio da autoridade pública, como critério para definição do servidor público. já era anotada por Viveiros de Castro, Tratado da Ciência da Administração e Direito Administrativo. Jacintho Ribeiro dos Santos Livreiro - Editor. Rio de Janeiro. $3^{a}$ ed.. 1914, p. 559. nota 01 - "Nézard nota falta de precisão na teoria que distingue os funcionários propriamente ditos dos simples empregados, e Hauriou observa que no quadro geral dos funcionários é impossível estabelecer uma linha de demarcação acima da qual fiquem os funcionários. e em baixo os empregados. Além disso, continua Nézard. essa teoria contém frequientemente um erro jurídico. Não se pode distinguir os empregados dos funcionários pelo fato de competir unicamente a estes últimos a autoridade pública, porquanto todos os agentes de gestão gozam da qualidade de funcionários. e entretanto 
nĩo exercem o poder público. É igualmente impossível fazer desta distinção uma questão de grau de elevação na hierarquia administrativa. porque assim ter-se-ia de dar a qualidade de funcionário ao guarda - campestre e recusá-la ao chefe de seção dum ministério. sendo, aliás. a função social do segundo muito mais importante do que a do primeiro. O mesmo argumento nos permite repelir o critério deduzido do direito de decisão próprio. Todo agente da força pública que lavra um processo verbal tem uma iniciativa mais considerável do que o chefe de repartição, que apenas prepara as decisões submetidas à assinatura do ministro. ou transmite as ordens de seu chefe hierárquico aos empregados subalternos. (... ${ }^{*}$. Se a dificuldade conceitual já se encontra presente, desde os primórdios. quando o objeto do estudo é o âmbito interno da estrutura administrativa estatal. que dirá quando esta cambia, ou tenta cambiar, suas funções e/ou atividades com o âmbito externo àquela estrutura, ou seja. o setor privado? Não à toa, ao referir-se à terceirização. JORGE ULISSES JACOBY FERNANDES, A Terceirização no Serviço Público, in Revista RH n. 2. Brasília. Centro Brasileiro para Formação Política. jul./1996. p. 11. apud CARLOS MOTTA/JORGE JACOBY/JAIR SANTANA/LÉO ALVES. Responsabilidade Fiscal, Del Rey. Belo Horizonte. 2000, p. 361. afirma que "os limites desse instrumento permitem vislumbrar a fronteira final do serviço público...". Lembre-se, ainda. da advertência de ALBERTO NOGUEIRA. Viilgem ao Direito do Terceiro Milênio. Renovar. Rio de Janeiro. 2001. p. 180. de que "nào há mais espaço livre em lugar nenhum, os espaços públicos se tornaram totais. a cidade moderna é uma cidade de espaços intercalados. E se não compreendermos isso em termos de Direito, não teremos como entender o fenômeno. nem como propugnar por um Sistema Jurídico que dando seguimento a um paradigma como esse da nossa Constituição de 1988 , que tem lá os seus defeitos, mas as virtudes são enormes diante desses defeitos. Se não entendermos isso. estaremos simplesmente caminhando para trás. E o jurista sempre foi um homem que tem a visão voltada para a realidade de hoje e para a realidade de amanhã. (...)"

(2) ODETE MEDAUAR, Direito Administrativo Moderno, Editora Revista dos Tribunais. São Paulo. 1996. p. 295.

(3) Idem. p. 296.

(4) PEDRO NUNES. Dicionário de Tecnologia Jurídica. Biblioteca Jurídica Freitas Bastos, Rio de Janeiro. 1982. 11 a. ed.. p. 822.

(5) JOSÉ DOS SANTOS CARVALHO FILHO. Direito Administrativo. Lumen Júris. Rio de Janeiro. 1999. 4" ed.. p. 401. nota 06.

(6) HELY LOPES MEIRELLES. Direito Administrativo Brasileiro, Ed. Revista dos Tribunais. São Paulo, 1991. $16^{\mathrm{a}}$ ed.. $2^{\mathrm{a}}$ tir.. p. 354.

(7) Idem, p. 70.

(8) CELSO ANTÔNIO BANDEIRA DE MELLO. Regime Constitucional dos Servidores da Administração Direta e Indireta. Ed. Revista dos Tribunais, São Paulo. 1991, $2^{\text {a }}$ ed.. p. 51.

(9) Op. cit.. p. 559/560.

(10) CAIO TÁCITO, Senvidor Público - Autarquia - Sigilo Funcional, in Temas de Direito Público. Renovar. Rio de Janeiro. 1997. $2^{\circ}$ v.. p. 1.494.

(11) MARIA SYLVIA ZANELLA DI PIETRO. Direito Administrativo. Ed. Atlas, São Paulo, 1996. p. 354. 
(12) Idem, p. 355, "fine"/356.

(13) Op. cit., p. 365.

(14) DAMÁSIO E. DE JESUS, Direito Penal, Ed. Saraiva, São Paulo, 1989, $2^{a}$ ed., p. 102.

(15) JÚllo FABBRINI MIRABETE, Manual de Direito Penal, Ed. Atlas S/A, São Paulo, 2000, $14^{\mathrm{a}}$ ed., $2^{\mathrm{a}}$ tir., p. 296.

(16) Boletim de Direito Administrativo, ADCOAS, novembro de 1992, p. 678.

(17) HELY LOPES MEIRELLES, op. cit., p. 67: "Agentes poíticos são os componentes do Governo nos seus primeiros escalões, investidos em cargos, funçōes, mandatos ou comissões, por nomeação, eleição, designação ou delegação para o exercício de atribuições constitucionais. Esses agentes atuam com plena liberdade funcional, desempenhando suas atribuições com prerrogativas e responsabilidades próprias, estabelecidas na Constituição e em leis especiais. Não são servidores públicos, nem se sujeitam ao regime jurídico único estabelecido pela Constituição de 1988. Têm normas específicas para sua escolha, investidura, conduta e processo por crimes funcionais e de responsabilidade, que lhes são privativos."

(18) Agentes Públicos na Emenda Constitucional 19/98", in Revista Ciências Sociais, UGF, vol. 4, n. 02, dezembro 1998, p. 43.

(19) Direito Tributário Brasileiro" ,. Forense, Rio de Janeiro, 1981, $10^{\mathrm{a}}$ ed., p. 620.

(20) FRANCISCO MAURO DIAS, op. cit., p. 235: "Os deveres de lealdade institucional e de guarda de sigilo sobre assunto da repartição entrelaçam-se intimamente e repousam, imbricados, sobre o princípio, hoje constitucionalizado, da moralidade administrativa." (grifos no orignal) E mais adiante, às fls. 243, transcrevendo trecho de Parecer exarado por THEMÍSTOCLES BRANDÃO CAVALCANTI: "O princípio da ética profissional, inerente ao exercício de qualquer profíssão, que se torna mais acentuado quando envolver o desempenho de função pública, pela responsabilidade social que a caracteriza, compreende uma série de procedimentos e atitudes éticas a que o servidor público fica, naturalmente, jungido como decorrência natural de sua investidura em função pública".

(21) DIOGO DE FIGUEIREDO MOREIRA NETO, op. cit., p. 185/186: “A subsidiariedade é um conceito em alta, originado na prática federal suiça; exaltado no magistério pontifício, na Encíclica Quadragésimo Anno, publicada em 15 de maio de 1931 na qual o Papa Pio XI ofereceu um enunciado; apontado como inspirador da Lei Fundamental da República Federal da Alemanha e aplicado explicitamente pelo Tratado de Maastricht, o documento maior na União Européia. O núcleo deste princípio consistem em reconhecer a prioridade da atuação dos corpos sociais sobre os corpos políticos no atendimento de interesses gerais, só passando cometimentos a estes depois que a sociedade, em seus diversos níveis de organização, demandar sua atuação subsidiária. Este princípio aponta, assim, para a delegação social como forma de devolver à sociedade organizada todas as atividades que, não obstante serem de definido interesse público, não necessitem de tratamento político — burocrático nem exijam ordinariamente o emprego do aparelho coercitivo estatal. Pode-se afirmar que, pela delegação social, o Poder Público retrai-se a uma atuação subsidiária da atividade gestora das entidades privadas." 